\title{
MAL-ESTAR DOCENTE E EDUCAÇÃO EM TEMPO INTEGRAL: CENÁRIOS DE UM BRASIL PROFUNDO
}

\author{
Jonatas Silva Santiago* \\ Úrsula Cunha Anecleto** \\ Ivana Carla Oliveira Sacramento***
}

Resumo:Este artigo tem como objeto de estudo o mal-estar docente e sua influência na construção da identidade do professor que atua no Programa Educação em Tempo Integral (ProEi), em uma escola pública do interior da Bahia. Busca entender como os novos papéis atribuídos à educação escolar, a partir das configurações sócio-educacionais do Programa, desafiam o professor com as demandas de sua profissão, interferindo na construção de professoralidade. Diante dessa problemática, este estudo objetiva discutir cenários de um Brasil profundo em relação às causas que aprofundam o mal-estar docente numa escola em tempo integral e seus reflexos no processo de construção da identidade e da professoralidade do professor. Espera-se contribuir com problematizações sobre a nova dinâmica escolar, a partir da implantação do ProEi, no sentido de superação desse mal-estar a partir da valorização e da ampliação da formação do professor.

Palavras-chave: Mal-estar docente. Identidade docente. Educação em tempo integral. Professoralidade/Profissionalidade docente.

\section{TEACHING AND FULL-TIME EDUCATION: SCENARIOS OF A DEEP BRAZIL}

\begin{abstract}
This article aims to study teacher malaise and its influence in the construction of the identity of the teacher who works in the Integral Time Education Program (ProEi), in a public school in the interior of Bahia. It seeks to understand how the new roles assigned to school education, from the socioeducational configurations of the Program, challenge the teacher with the demands of his profession, interfering in the construction of teacherality. In the face of this problem, this study aims to discuss scenarios of a deep Brazil in relation to the causes that deepen teacher malaise in a full-time school and its reflexes in the process of teacher's identity and teacher's construction. It is hoped to contribute with problematizations about the new school dynamics, from the implantation of the ProEi, in the sense of overcoming this malaise from the appreciation and the amplification of the teacher training.
\end{abstract}

Keywords: Teacher malaise. Teaching identity. Full-time education. Professor/Teaching professionalism.

Submissão: 30-05-2019 Aceite: 04-08-2019

\section{INTRODUÇÃO}

Um dos maiores desafios do mundo profissional e corporativo é ser competente. E o que significa isto nesta sociedade competitiva e dinâmica em que vivemos? Não resta

1 *Mestrando no Programa de Pós-graduação Mestrado Profissional em Educação e Diversidade (MPED/UNEB). Especialização em Estudos Literários (UEFS) e em Psicopedagogia (UEFS). Pesquisador do Grupo de Estudos e Pesquisa em Multiletramentos, Educação e Tecnologias(GEPLET/UNEB).Docente da Educação Básica pela Secretaria de Educação do Estado da Bahia (SECBA).

$2{ }^{* *}$ Doutora em Educação pela Universidade Federal da Paraíba (UFPB). Mestra em Crítica Cultural pela Universidade do Estado da Bahia (UNEB). Docente do Departamento de Educação da UNEB/Campus XIV e do Programa de Pós-graduação Mestrado Profissional em Educação e Diversidade (MPED/UNEB), Vice-líder do Grupo de Estudos e Pesquisa em Multiletramentos, Educação e Tecnologias (GEPLET/UNEB).

$3{ }^{* * *}$ Doutora em Língua e Cultura (UFBA), na linha de pesquisa Aquisição, ensino e aprendizagem de línguas. Mestra em Crítica Cultural, na linha de pesquisa Letramento, identidades e formação de professores, pela Universidade do Estado da Bahia (UNEB). Especialista em Estudos Literários (UNEB), graduada em Letras Vernáculas com Inglês (UNEB). É docente da Secretaria de Educação do Estado da Bahia. 
dúvida que a resposta a esta pergunta está cada dia mais difícil de alcançar consenso, principalmente quando se aplica ao campo educacional. Para Zabala (2010, p 40), "Ser competente é, ao agir, mobilizar, de forma integrada, conhecimentos e atitudes mediante uma situação problema, de forma que a situação seja resolvida com eficácia".

O autor define competência como a capacidade decorrente do conhecimento que alguém tem sobre um assunto. É a soma de conhecimentos ou habilidades. Nota-se aí que, até pela etimologia da palavra e sua evolução na história, tem-se aumentado os requisitos para que alguém seja adjetivado de competente e, no que tange o educador, se torna ainda mais desafiante quando relacionamos o conceito do termo ao contexto e sujeitos do processo educativo no ambiente escolar.

Para entendermos o tamanho do desafio do educador nos tempos atuais e os dilemas vividos por aqueles que perseguem um status ideal de competência, precisamos nos concentrar no termo situação problema (ZABALA, 2010), que contém a ideia de algo sempre imprevisível. Aliás, essa ideia caracteriza o ambiente escolar, pois seus atores (alunos, professores, funcionários, família) são oriundos de diversos contextos sociais, em que paradigmas são ressignificados, constantemente.

Quando pensamos nas questões que dizem respeito ao desenvolvimento do país, é quase automático ouvirmos das pessoas, em diferentes esferas da vida social, que a educação é o caminho para o aprimoramento da sociedade e para o crescimento econômico. Afinal, um país que não investe, ou que investe muito pouco nas escolas, não deve conseguir tornar-se uma nação das mais desenvolvidas. Não é estranho que grande parte das pessoas pense assim, visto que o conhecimento, no mundo contemporâneo, está diretamente associado à circulação do saber nos ambientes privilegiados da sociedade, os quais definem quem pode dizer o quê, onde e para quem. Nesse sentido, a educação tem sido privilégio de apenas poucos.

Já há muito se discute, no entanto, que a educação no nosso país enfrenta sérios problemas que afetam inteiramente a sua dinâmica de funcionamento, o que compromete, na mesma proporção, a sua função de promover a cidadania e a inclusão social. Grande parte das discussões concentra-se, sobretudo, no papel do professor como agente desencadeador da mudança.

No entanto, os órgãos reguladores do Estado, através de suas portarias, decretos e programas/projetos, exercem pressão sobre o professor, de forma implícita, com seus avaliadores externos, ampliação na demanda de trabalhos etc., aumentando, assim, as responsabilidades no espaço escolar, colocando nas mãos do docente mais uma tarefa 
que demanda conceitos subjetivos de competência e desempenho, causando um sentimento de impotência e até incapacidade diante dos índices não alcançados.

Diante desse cenário, percebemos, pelos resultados deste estudo, que a identidade do educador está em franca crise, sendo questionada até por ele mesmo, que vive uma sensação de que as tarefas realizadas na escola ainda são insuficientes para a efetivação de seu trabalho pedagógico, principalmente diante das atividades advindas da sociedade atual, que não param de adentrar o espaço escolar. O docente, diante de tantas cobranças, se vê impotente e desamparado pelo poder público e outros organismos sociais que se limitam a transferir para a escola a missão de formar o cidadão por inteiro, de forma integral, e pronto para intervir para a mudança da sociedade, gerando, assim, um mal-estar docente.

Esse mal-estar o desestabiliza quase que constantemente no exercício de sua profissão. Para Esteve (1999, p. 120), “[...] a chave do mal-estar docente está na desvalorização do trabalho do professor, evidente no nosso contexto social, e nas deficientes condições de trabalho do professor na sala de aula [...]". Dessa forma, engloba comportamentos que expressam insatisfação profissional, alto nível de estresse, desejo de abandonar a carreira etc., fatores que geram desmotivação de professores e interferem na sua qualidade de ensino.

Esse sentimento de insatisfação profissional não ocorre apenas com docentes que atuam na educação em tempo integral. No entanto, essa situação tem se acentuado nesse programa, tendo em vista que professores ampliam suas funções (e carga horária) na escola, que vão além de aspectos didático-pedagógicos. E, mesmo construindo uma autoimagem que questiona a sua própria competência, pesquisas sobre a formação docente (KLEIMAN, 2001; MENDES, 2008; BUNZEN, 2009) destacam, por um lado, a agentividade do professor e, por outro, questionam essa imagem negativa que circula socialmente.

\section{CONTEXTUALIZAÇÃO DO OBJETO DE PESQUISA: EDUCAÇÃO EM TEMPO INTEGRAL E MAL-ESTAR DOCENTE}

Para se falar em Educação em Tempo Integral é preciso diferenciar alguns conceitos sutis envolvidos. O termo Educação em Tempo Integral ou Escola de Tempo Integral diz respeito àquelas escolas e secretarias de educação que ampliaram a jornada escolar de seus estudantes, trazendo (normalmente) novas disciplinas para o currículo escolar. A maioria das unidades de ensino que adota esse modelo geralmente 
implementa a extensão do tempo em turno e contra-turno escolar; em um turno, os discentes estudam as disciplinas do currículo básico, como Português, Ciências, História, Geografia, Inglês e Matemática, e o outro período é utilizado para aulas do currículo diversificado, que compreende componentes, tais como artes audiovisuais, educação musical, esportes, dança, tecnologias da informação e comunicação etc.

Na perspectiva da educação integral, o conceito em tempo integral suscita várias discussões, uma vez que há algumas abordagens dos movimentos sociais ligados à educação que defendem que apenas a ampliação do tempo de estudo não garante o resultado ambicionado pela educação integral no ensino e na aprendizagem dos estudantes - resultado este que deseja garantir o pleno desenvolvimento de competências e habilidades dos estudantes, compatíveis com a maturidade cognitiva de crianças e de adolescentes.

Dessa forma, a educação em tempo integral é mais do que ampliar a permanência do aluno no espaço da escola. Isso porque o aumento do tempo na sala de aula não é o suficiente para ampliar competências cognitivas e sócio emocionais importantes aos educandos; é preciso repensar o modelo de educação proposto como novo e revolucionário para não ser "apenas mais do mesmo".

Ressaltamos que uma educação em tempo integral tem como base a ideia da educação integral dos sujeitos. Ou seja: parte-se da concepção da necessidade de desenvolvimento dos alunos em relação às dimensões intelectual, física, moral, emocional, social e cultural, no sentido de propiciar a construção de um projeto de vida para eles. Dessa forma, espera-se, em uma proposta de educação integral, a formação humanista dos alunos, que tenha como princípio

[...] uma escola única, destituída de dualidades, como exemplo: estudo $\mathrm{x}$ trabalho; teoria x prática; trabalho intelectual x trabalho manual; mente $\mathrm{x}$ corpo; conhecimento acadêmico x conhecimento cotidiano etc. Essa abordagem permite uma maior aproximação da escola com a vida o que ocasiona uma participação mais ativa dos indivíduos na sociedade [...] (CUNHA, 2012, p. 9).

A educação integral apresenta um conceito abrangente e, dependendo do contexto em que é usado, pode revelar disputas de concepções e de práticas (COELHO, 2010). O ProEI, então, baseia-se em três dimensões essenciais: tempo, espaço e conteúdo. Entretanto, a educação integral - assim como a educação em tempo integral apresenta em sua abrangência relação entre tempo (ampliação da jornada escolar) e espaço (relação com os territórios onde a escola está situada).

Para Cavaliere (2007), o tempo é um elemento fundamental para os processos 
civilizatórios. Compreender o caráter relativo, contingente do tempo da escola é, na verdade, compreender sua gênese histórica, muitas vezes obscura, pelo fato de que os modelos escolares têm ultrapassado longos períodos, com lentas transformações. No entanto, segundo Elias (1998, p. 12), a complexidade da abordagem teórica do tempo deve-se ao fato de que essa categoria constitui uma forma de relação e não um fluxo objetivo: "[...] não basta fazer do tempo um objeto, tanto da sociologia como da física ou em outras palavras, como muitas vezes se faz, contrastar um tempo 'social' com um tempo "físico"”. O tempo, seja ele "físico" ou "social", não pode ser considerado em sua objetividade ou substancialidade. Ele é sempre um conjunto de relações entre diferentes dimensões que compõem um determinado contexto histórico.

Na Educação em Tempo Integral, a noção de tempo é entendida como tempo integral: momento da jornada escolar, quando alunos estão em atividades pedagógicas, intraescolares ou extraescolares. Durante esse tempo, os atores educacionais (professores, funcionários, gestão, pais/responsáveis) tornam-se responsáveis pelos estudantes em seu percurso educativo. Mas, para isso, é preciso considerar o contexto do advento da obrigatoriedade escolar, da exigência crescente de mais altos níveis de escolaridade, da profissionalização dos professores e padronização dos sistemas nacionais de ensino, fatos que produziram mudanças marcantes na gestão do tempo dos indivíduos, conformando uma nova ordem do tempo social.

A ampliação de tempo na escola parte do pressuposto de valorização e fortalecimento de práticas educativas, otimizando ambientes e construindo uma cultura de preservação, potencialização e respeito ao seu relevante papel na transformação social das pessoas que dela precisam. Nesta vertente, o profissional da educação se torna peça chave para a promoção desse programa de ensino, pois a ampliação de tempo de aprendizagem implica adotar outros espaços educativos que fazem parte da comunidade do entorno e seus equipamentos públicos, como praças, associações, coretos, jardins etc. como ampliação do espaço escolar para atender à demanda de atividades necessárias para a diversidade de proposta e ocupação do tempo.

As ações temporais são materializadas em espaços físicos tanto no ambiente escolar quanto além de seus muros. Destarte, esses espaços devem acolher e proporcionar condições para o desenvolvimento de práticas pedagógicas e atividades sócio-culturais. Também, como afirma Julião (2000), devem oportunizar o desenvolvimento de competências dos alunos, promover a identidade pessoal e sentimento de pertencimento, os movimentos corporais, o contato social, a privacidade, 
a confiança etc.

Assim, na perspectiva da educação em tempo integral, tem-se um espaço nuclear para a atividade pedagógica (sala de aula) que necessita ser ampliado para outras atividades educacionais, tais como para as vivências das artes, dos esportes, da cultura ou de outras vivências e experiências sociais. Espera-se que docentes utilizem outros ambientes, a exemplo de bibliotecas, pátio, quadra de esportes, corredores da escola etc. como também oportunize aos alunos conhecer o lugar onde eles moram e se apropriar de espaços públicos para a construção de conteúdos significativos para a formação educacional discente.

Em relação ao conteúdo, embora apresente aspectos na perspectiva da construção de conhecimento e a aprendizagem cognitiva, esse projeto "não representa um 'modelo' pronto e concluso de um Programa de Educação Integral,mas, ao contrário, representa um primeiro plano, com bases conceituais e operacionais de uma proposta que será grandemente ressignificada" (BAHIA, 2014, p. 16).

É neste sentido que o documento destaca, no item "Metas", o comprometimento da Secretaria de Educação em promover, ao longo do ano letivo, "ações de formação continuada para os profissionais das UE com o ProEI" (BAHIA, 2014, p. 18), além da ressignificação da prática pedagógica do docente através de um currículo adequado à formação integral dos alunos, que leve em conta tempo e espaço/conteúdo.

Enquanto o escopo do ProEI visa reforçar e aprofundar a formação política e social dos alunos enquanto cidadãos por meio de componentes sócio-político-culturais, tais como Educação e Cidadania, Educação e Direitos Humanos, Educação Científica, muitos docentes que atuam no programa (e na escola colaboradora desta pesquisa), ainda não familiarizaram-se com as vertentes político-ideológicas que regem o programa. O resultado disso é a atuação de professores que foram preparados, ao longo de sua formação, para as disciplinas mais tradicionais no currículo - Matemática, Geografia, Física, Ciências, Língua Portuguesa - lecionando novos conteúdos/abordagens que requerem, para tal, outras estratégias para o ensino.

Talvez isso aconteça visto que os programas de formação, em sua maioria, são elaborados por especialistas e técnicos que, embora tenham conhecimento sobre os conteúdos programáticos dos temas a serem trabalhados, não necessariamente levam em consideração especificidades dos projetos pedagógicos das escolas, o planejamento e as carências dos professores, as características dos alunos, as realidades locais, enfim, todo o contexto que envolve as situações do cotidiano das salas de aula. Ademais, 
consideramos que a formação continuada tem mantido, em geral, o caráter emergencial que sempre lhe foi atribuído com o tempo. Portanto, talvez estejamos naturalizando situações e realidades que encontramos cotidianamente nas nossas escolas.

Além da falta de expertise para lecionar alguns componentes, muitos professores são levados a ministrar aulas com os poucos recursos pedagógicos/técnicos disponíveis, de acordo com o esforço pessoal, refletindo numa oscilação no desenvolvimento do processo de ensino. Nesse contexto, alguns conseguem organizar-se de forma mais confortável se, por exemplo, a sua disciplina adicional é afim com a área de formação imaginemos a disciplina de "Educação e Cidadania": um professor da área de humanas, em tese, terá mais facilidade para atuar com esse componente -. Outros docentes, no entanto, ainda estão buscando a identificação com os novos componentes.

Outra situação que reflete o cenário do Brasil profundo no espaço escolar do ProEi é a falta de investimento e readequação de espaço físico da unidade escolar. Trata-se de uma necessidade real, uma vez que o Programa tem como característica a ampliação do tempo de permanência do aluno na escola e a diversificação dos espaços de aula. Portanto, é preciso que a escola invista em uma maior diversidade de espaço físico, proporcionando mais conforto e equipamentos educativos para professores e alunos.Assim, esses fatores também contribuem para a geração de um mal-estar no espaço escolar, fragilizando, dessa forma, a identidade do professor.

\section{MAL-ESTAR, PROFESSORALIDADE E IDENTIDADE DOCENTE}

A expressão "mal-estar docente" (ESTEVE, 1987) nasce justamente como um conceito da literatura pedagógica que pretende resumir o conjunto das reações dos professores como grupo profissional desajustado devido à mudança social. Também, refere-se a uma fase de desencanto provocada por uma desvalorização da formação de professores. Essa concepção encontra eco na opinião de autores, como Barton e Walker (1984); Blase (1982), que já assinalavam a presença do termo produzido pela junção de vários fatores sociais e psicológicos que atinge o professor.

Nos últimos trinta anos, o mal-estar vem sendo estudado por vários campos do saber, a exemplo da Pedagogia, Psicologia, Psicanálise e tem gerado numerosas referências nas principais bases de dados de pesquisa sobre educação, dada à sua incidência e aos efeitos visíveis na saúde e na rotina de professores. Esse termo "se emprega para descrever os efeitos permanentes, de caráter negativo, que afetam a personalidade do professor como resultado das condições psicológicas e sociais em que 
exerce a docência, devido à mudança social acelerada" (ESTEVE, 1987, p. 71).

Um dos fatores que tem gerado esse mal-estar é, sem dúvida, a radical e crescente mudança gerada pela passagem de um sistema de ensino voltado para a elite econômica, que primava pela qualidade com pequena quantidade de alunos, para um sistema de ensino de massa, implicando o aumento quantitativo de alunos e de professores. Então, ao invés de uma escola com pretensa homogeneidade, agora se depara, de fato, com salas de aula heterogêneas, não apenas no que diz respeito à maturidade cognitiva, mas também em relação a marcas pessoais, heranças culturais e problemas de ordem social e política que acompanham os nossos estudantes, demandando atendimento personalizado e respostas rápidas para situações que fogem à competência da escola e, também, do professor.

Os tempos mudaram e, no decorrer dos anos, muitas mudanças sócio-políticas envolveram a escola em uma atmosfera de reestruturação de seus papéis que, para atender às novas demandas, absorveu funções cada vez mais complexas e de difícil atendimento. A dúvida se instaura e a competência do professor é questionada, pois a escola da transição precisa dar uma resposta às novas demandas sociais. É na escola, mediada pelas micro e macro relações, que os professores exercem a profissão. Estas relações demarcam o campo de tensão no qual a práxis dos professores lhes possibilita constituir a professoralidade ${ }^{4}$ docente, tanto na singularidade, quanto na coletividade (ANDRÉ, 2013).

Dessa forma, o mal-estar docente atrai elementos para o debate que vão além da função do professor, como o sentimento de pertença e a professoralidade em exercício e, ao mesmo tempo, amplia o campo de atuação deste profissional dada a sua importância na consolidação de uma sociedade que traz ainda marcas da anterior sociedade industrial- e já aponta para uma sociedade de constituição em rede, que nos parece dar melhor e mais eficiente resposta às demandas da escola com múltiplas configurações do conhecimento.

Outrossim, as avaliações institucionais regidas por normas e portarias dos órgãos reguladores da Educação (Ministério da Educação - MEC, Secretarias de Educação - SEC etc.) exercem monitoramento que, muitas vezes, não são tão claros para o professor; alunos dialogam com outras linguagens, portadores textuais e

4 O conceito de professoralidade, evidenciado nos estudos de Isaia e Bolzan (2008, p. 110), pode ser definido como "um processo que implica não só o domínio de conhecimentos, de saberes, de fazeres de determinado campo, mas também a sensibilidade do docente como pessoa e profissional em termos de atitudes e valores, tendo a reflexão como componente intrínseco ao processo de ensinar, de aprender, de formar-se e, consequentemente, de desenhar sua própria trajetória". 
realidades extra-escolares para os quais professores não se sentem tão proficientes, tornando-se, por isso, aos olhos desse docente, exigentes e pouco motivados aos estudos; famílias ausentes do processo de formação dos filhos; problemas relacionais e pessoais são fatores que, na atualidade, fazem parte da rotina da escola e, por isso, compõem a professoralidade docente.

Nesse sentido, Tardif (2003) apresenta que os saberes da docência são plurais, temporais, sociais e históricos e, exatamente por isso, são difíceis de mensurar. Existem cobranças institucionais por um padrão e ranking nacionais que impelem os docentes a sempre e continuamente se refazerem em suas competências, ampliando, cada vez mais, a professoralidade. Isto produz uma sensação de incompletude e, diante dos fatores elencados, de ineficiência.

De maneira geral, isso resulta de certa homogeneização dos processos de formação docente, os quais, com raras exceções, são reforçados por pressupostos teóricos inovadores, legitimados pela "ciência", e deixam em segundo plano os sujeitos que estão ali em questão: professores e alunos. Afinal, não basta apenas ter conhecimento teórico para que um professor possa atuar, de modo competente, na complexa realidade educacional que o cerca. Ele necessita, entre outras coisas, compreender essa realidade, interpretá-la no sentido de poder decidir, de modo autônomo e crítico, por meios para intervir e promover mudanças.

Além disso, os órgãos reguladores da Educação (Ministério da Educação MEC, Secretarias de Educação - SEC etc.), em certa medida, desconsideram a dimensão formativa do professor no que diz respeito a suas ações políticas, vez que tal dimensão - além da acadêmica - é também responsável pelas inovações que ele imprime em sua prática cotidiana, porque se baseiam na reflexão e na contínua análise de sua realidade profissional. Nesse sentido, as descontinuidades de propostas curriculares, assim como o distanciamento delas das experiências situadas dos professores, por vezes, fazem com que os cursos de formação continuada, por exemplo, sejam uma pressão para os docentes

No entanto, apesar de todas essas situações, o professor é visto, conforme apresenta Sacristán (1995), como um sujeito imprescindível para a efetivação da atividade docente nos ambientes formais. Ora, se dele depende o efetivo fazer pedagógico, há uma relação sine qua nom para a educação formal se este profissional não se reinventar a cada novo desafio. Podemos afirmar que não existe educação efetiva se este processo não passar, de maneira cíclica, por este docente e sua história num 
constante devir. Isso perpassa pelas características do ser professor, seja em seu percurso formativo ou sua trajetória profissional.

Temos diante de nós um dilema em pelo menos dois movimentos: um que parte dos elementos subjetivos da formação heterogênea do professor; outro que converge para a ambiência escolar com todos os fatores externos e de contexto social que envolve a práxis docente e que aponta para este mal-estar instalado neste ambiente.

Diante desse cenário, a identidade do educador está em franca crise, sendo questionada até por ele mesmo, que vive uma sensação de que as tarefas realizadas na escola ainda são insuficientes para a efetivação de seu trabalho pedagógico, principalmente diante das demandas advindas da sociedade contemporânea, tais como a necessidade de constante atualização de conhecimentos, novidades tecnológicas, fugacidade do tempo e relatividade de conceitos, potencializando a inversão de valores, que não param de adentrar o espaço escolar.

As principais consequências desse mal-estar docente estão relacionadas ao acelerado processo das transformações sociais que ocorrem em ritmo algumas vezes mais rápido que o sistema educacional é capaz de acompanhar, a partir da disseminação das tecnologias da informação e comunicação, da implementação de programas e projetos governamentais que nem sempre atingem as reais necessidades educacionais, o que incide diretamente no trabalho do professor, colocando-o diante de uma constante necessidade de formação e de atualização profissional.

A tarefa dada aos docentes é muito abrangente e, considerada por eles, de difícil realização (a exemplo da formação holística na educação em tempo integral) e, nessa situação, eles se sentem pressionados e exigidos, mas, em sua visão, escassamente apoiados e valorizados pelos governos e sociedade de modo geral. Assim, entendemos que a dimensão de sua tarefa é bem mais ampla do que apenas transmitir conhecimento, função atribuída ao docente durante muito tempo, quando se centrava no processo de ensino, considerado por Freire (1992), como educação bancária.

Diante de tudo isso, o mal-estar docente o desestabiliza quase que constantemente no exercício de sua profissão. Para Esteve (1999, p. 120), “[...] a chave do mal-estar docente está na desvalorização do trabalho do professor, evidente no nosso contexto social, e nas deficientes condições de trabalho do professor na sala de aula". Dessa forma, engloba comportamentos que expressam insatisfação profissional, alto nível de estresse, desejo de abandonar a carreira etc., fatores que geram desmotivação de professores e interferem na construção de sua identidade. 
No entanto, isto não é de todo ruim, pois, a partir desse sentimento de incerteza, o profissional pode problematizar sua prática docente e refletir sobre as tendências educacionais e temas atuais que mantêm o seu exercício cotidiano à frente de seu tempo, com uma abordagem compatível com as expectativas de seus alunos (e da sociedade de modo geral), potencializando, então, o desenvolvimento da identidade e professoralidade docente.

Não obstante, é em face desses aspectos quase que fugidios das noções de identidade e de profissionalidade que tais conceitos devem ser, de algum modo, discutido, ainda que não por um recorte sobre a temática único diante de outros possíveis pontos de vista. É preciso notar, por outro lado, que a identidade do professor não é definida somente a partir do momento em que se adquire uma formação acadêmica em cursos de licenciatura, como se esta exigência legal e o acúmulo de conhecimento científico em bancos universitários fossem suficientes para definir, em seu íntimo, o que é ser professor e como um professor vê a si mesmo.

A identidade do professor deve ser discutida em uma profundidade que perpassa a compreensão técnica de uma profissão. Deve ocorrer a partir de uma transformação contínua e refletida em relação a complexas situações e fatos que envolvem a escola, o educando e sua família. Assim, entendemos que a professoralidade do professor deve ser pensada dentro de uma articulação com a sua identidade, levando-se em conta o caráter fluido, cambiante, contraditório desse processo de construção identitária.

A construção da identidade docente, portanto, figura-se a partir de sua ação e de aspectos subjetivos e do espaço extraescolar. No espaço escolar, é importante que o docente leve em conta que a experiência da escola pública básica tem por finalidade desenvolver a formação cidadã e crítica do educando (PONTE, 2008). Nesse sentido, vê-se que a escola (principalmente a partir da ação do professor) deve garantir não só as condições para que os alunos adquiram conhecimento formal dos conteúdos (um dos aspectos da professoralidade docente), mas também uma prática curricular que garanta também a formação humanística, voltada para a prática social, subjetiva e para a cidadania. O papel docente, portanto, é atravessado por essa concepção de educação, contribuindo, assim, para a construção e reconstrução de sua identidade e, consequentemente, da professoralidade. Dessa forma, Pimenta (1997, p. 6) afirma que

Dada a natureza do trabalho docente, que é ensinar como contribuição ao processo de humanização dos alunos historicamente situados, espera-se da licenciatura que desenvolva, nos alunos, conhecimentos e habilidades, 
atitudes e valores que lhes possibilitem, permanentemente, irem construindo seus saberes e fazeres docentes, a partir das necessidades e desafios que o ensino, como prática social, lhes coloca no cotidiano.

O que está subjacente aqui é uma compreensão de escola contemporânea que não se compraz em ofertar ao educando, por exemplo, simplesmente uma soma de fatos, mas, entre outras coisas, de garantir-lhe a capacidade de entender as principais características metodológicas e epistemológicas de uma disciplina para entender de forma mais criativa esses mesmo fatos, conseguindo, assim, construir de modo ativo um pensamento crítico. Essa educação permite que o educando consiga desenvolver-se criticamente, garantindo aptidões intelectuais no enfrentamento de problemas cotidianos e na vida prática.

Ora, esse tipo de entendimento não passa ao largo da experiência docente: o professor é então inserido dentro de um contexto muito mais complexo do que o simples saber-fazer adquirido anteriormente no seu preparo profissional. Se a escola, portanto, não se atém somente à demanda curricular e no cumprimento do dever de "reproduzir" conteúdos, isto significa que ela deve ser pensada em um aspecto transitório na medida em que é frequentemente afetada pelo próprio tempo histórico, pelas principais demandas da contemporaneidade e problemas enfrentados pela sociedade e até por sua comunidade local.

É dessa maneira, portanto, que a identidade do professor é construída, de modo contínuo, em andamento com o seu próprio fazer docente que, como vimos, não se faz somente na reprodução do conteúdo, mas na sua participação enquanto mediador em um processo ainda mais amplo, visando, assim, à formação humanística do aluno.

O conceito de identidade docente absorve a energia do cotidiano escolar em sua complexidade. Dessa forma, não se pode pensar em uma identidade constituída fora da própria prática pedagógica e da experiência do professor; ou seja, fora de sua própria professoralidade. Sobre isso, Pimenta (1997, p. 7) apresenta que

[...] a construção da identidade docente não pode dissociar-se dos valores de cada indivíduo, nem das experiências vividas ao longo da sua formação e da forma como cada pessoa constrói a sua história de vida, o que permite compreender que a identidade profissional se constrói e transforma num processo contínuo, podendo assumir características diferentes em distintos momentos da vida. Daí o falar-se não em identidade.

Entendida como processo, a identidade docente estrutura-se como elemento dinâmico e paradoxal (GUIMARÃES, 2004). Enquanto processo dinâmico está sempre em construção, a partir de ações interativas no espaço escolar e extraescolar. Ou seja: a 
identidade é construída, também, pela reflexão de sua práxis diária e de aspectos de sua professoralidade: reflexão sobre a atuação docente na sala de aula e suas reverberações no espaço externo à escola. Já quanto ao aspecto paradoxal, leva-se em conta o processo de identificação que o docente tem com sua profissão; a capacidade de mudança desse sujeito frente às necessidades sociais e educacionais.

O professor, então, amplia sua professoralidade ao entender-se enquanto sujeito de seu fazer docente. Para Oliveira (2003), a professoralidade corresponde ao processo de construção do sujeito professor (portanto, de identidade) ao longo de sua trajetória pessoal e profissional. Nesse sentido, envolve saberes teóricos a serem ensinados (conceitos, fatos, saberes culturais etc.) e saberes práticos (estratégias de ensino, práticas pedagógicas, metodologias etc.).

É nesse ínterim que a escola em tempo integral pode desempenhar um papel importante na construção da identidade do professor. As disciplinas são distribuídas em dois turnos, computando carga horária mínima de 7 horas/dia. Essa característica intensifica a participação de um mesmo docente na unidade escolar, favorecendo a sua inserção dentro de um contexto mais amplo, permitindo conhecer mais de perto a realidade dos alunos e da comunidade circunvizinha.

Isso pode fazer com que o docente consiga identificar com mais facilidade os limites e os êxitos de suas próprias práticas, servindo de formação continuada dentro de uma prática e não somente numa atualização de conteúdo teórico. Ao pensar a identidade do professor a partir da prática, Pimenta (1997) fala sobre formação continuada do docente para além de uma perspectiva estritamente centrada nos aspectos curriculares e disciplinares em seu próprio local de trabalho, em redes de auto-formação e em parceria com outras instituições. Assim, a escola em tempo integral é um lugar bastante privilegiado para o desenvolvimento da identidade e da professoralidade docente, em virtude do tempo dedicado aos discentes e a aproximação mais frequente entre escola e comunidade.

\section{CONSIDERAÇÕES SOBRE A ESCOLA EM TEMPO INTEGRAL}

Embora a ideia de um ensino em tempo integral, a princípio, seja um projeto bastante atrativo, os desafios para que seja posto em prática são igualmente complexos. Para tratar desse assunto, partiremos de duas ilações no que se refere à palavra "integral". Em primeiro lugar, "integral" aqui pode significar um aspecto mais 
quantitativo do ensino: os alunos passam cerca de sete horas, e não mais cinco horas, dentro da escola, fazendo a integração dos turnos matutino e vespertino.

Para tanto, a escola necessita de uma adequação física e técnica - refeitórios, alimentação balanceada, lugares de descanso para os alunos, novos equipamentos que serão utilizados em aulas multidisciplinares, quadra coberta etc. - que nem sempre é disponibilizada pelo Estado.

Em segundo lugar, tem-se o aspecto da formação humanística integral do aluno, através de um currículo adaptado a esse modelo que favoreça a formação "cognitiva, afetiva, histórico-social, cultural, artística, profissional, familiar e outros" (BAHIA, 2014).Nesse sentido, a escola cumpre duas funções básicas: retirar o aluno da vulnerabilidade das ruas e, em contrapartida, dar condições para uma formação em consonância com o seu projeto de vida.

Não obstante, não é o que se vê na prática, cuja prioridade tem sido aquele primeiro ponto (ampliação da jornada escolar), sem o acompanhamento da formação subjetiva dos alunos. Foi essa conclusão, por exemplo, a que chegaram Castro e Lopes (2011) em um estudo de caso a respeito da escola de ensino integral no Estado de São Paulo, implantado em 500 escolas, desde de 2006:

Enquanto para a Secretaria de Estado da Educação a justificativa da criação do projeto era a melhoria da qualidade do ensino, havia uma quase unanimidade, entre os diferentes sujeitos entrevistados, ao afirmarem que o governo instituiu a escola "para tirar as crianças da rua, com certeza". [...] Percebe-se, nitidamente, a partir dos depoimentos, que a intenção do governo teria sido resolver paliativamente, problemas sociais gerados pela ausência de políticas sociais [...]. (CASTRO; LOPES, 2011, p. 276)

Fica claro que, no contexto de São Paulo assim como no da Bahia, a priorização foi mais a integração temporal dos turnos, atendendo a alunos em condição de vulnerabilidade. Não houve, como apresentaram numericamente os autores, melhora substancial na qualidade educacional. Ademais, "ausência de passeios e excursões era uma reclamação constante nos depoimentos dos alunos, bem como o cansaço provocado por uma rotina de 9 horas baseada em lições escritas" (CASTRO; LOPES, 2011, p. 266).

Nesse sentido, podemos retirar como orientação que o simples aumento da permanência do aluno na escola por si só não é garantia de melhora do sistema educacional. Só deixará os alunos mais cansados. O efeito disso é um sentimento de desorientação por parte dos profissionais da educação, atingindo de forma incisiva a sua 
identidade e a autoestima, culminando em uma situação emocional que, por vezes, interfere na sua prática em sala de aula.

Isso porque se o estado prioriza a permanência integral do aluno no espaço escolar, sem sequer fazer os ajustes físicos, e não se preocupa em entender o contexto de vida dos discentes para oportunizar uma formação específica do docente, o profissional entenderá que o problema é consigo próprio, quando na verdade o equívoco está em um sistema que, por ter sido gerado sem a participação de atores escolares, não dialoga com reais necessidades educacionais.

Ora, estamos tratando, também, de novas disciplinas, cujas ementas ainda mais multidisciplinares devem ser ministradas para além de um estilo quadro-giz-aluno-caderno. E, na medida em que a escola em tempo integral é mais "sensível" às vicissitudes do mundo contemporâneo, porquanto lida com mais intensidade com o seu aluno, é mister que o professor receba uma formação continuada para esse engajamento.

Por fim, para ser mais pragmático, Ferreira (2016)apresenta três ações basilares para uma docência integral: i. a dialogicidade, que conduz a uma construção coletiva do conhecimento; ii. A contextualização, que se refere ao âmbito em que um conhecimento é estabelecido e as suas relações; iii. a diversidade, que seria uma abertura para pontos de vistas diferentes dentro do ensino. A partir dessas ações, apresentamos uma quarta que se torna essencial para a formação humana dos sujeitos:iv. a construção, pelo aluno, de um projeto de vida para curto, médio e longo prazo.

Mesmo diante de um cenário em que se preocupou mais com a ampliação do tempo do aluno na escola, é preciso que o professor se atenha àqueles conceitos/ações elencados por Ferreira (2016), bem como participe de grupos de pesquisa e intervenção dentro de sua unidade escolar para entender melhor a realidade da escola e construir espaços que dialoguem com esse cenário.

\section{ESCOLA EM TEMPO INTEGRAL NO ESTADO DA BAHIA}

“A essência da sua profissionalidade reside nesta relação dialética entre tudo que, através dele, se pode difundir - conhecimentos, destrezas profissionais, etc. - e os diferentes contextos práticos." (SACRISTÁN, 1999, p.74).Nesse sentido, não basta ao professor apenas ter técnica ou se adaptar às condições e aos requisitos impostos pelos contextos preestabelecidos pela docência; é preciso assumir uma perspectiva crítica e estimular a sua capacidade para adotar decisões estratégicas para intervir sobre diversas situações que acontecem no espaço escolar. 
Diante disso, é preciso estudar os fatores que causam e perpetuam o mal-estar emocional no docente, a fim de construir, colaborativamente, alternativas metodológicas que contribuam com a educação emocional do professor e potencializem a sua realização profissional e pessoal. É com essa perspectiva que se estruturam os princípios educativos da Escola em Tempo Integral.

Desde 2014, o estado da Bahia começou a implantar a Educação em Tempo Integral como programa de ensino na educação básica, em que adolescentes e jovens tiveram o seu tempo de permanência no espaço escolar ampliado, com um aumento de carga horária e inserção de disciplinas do eixo sócioemocional: projeto de vida, mapa socioeducativo, atividades integradoras, educação e cidadania, educação e direitos humanos etc., com vistas a uma formação humanística desses sujeitos.

Como característica, o eixo socioemocional propõe, através de seus componentes, a elaboração de um projeto de vida para o estudante, com ações a curto, médio e longo prazo, que leve em conta seus sentimentos, desejos, competências e vontades. Além disso, cabe à escola a tarefa de fazer o mapa socioeducativo dos estudantes, a fim de identificar os espaços potencialmente educativos no entorno da escola e na comunidade onde o aluno está inserido; assim, ampliamos o espaço e o tempo com conteúdos que emergem da cultura local e global.

Atividades de higiene pessoal, projetos pessoais e profissionais e problemas de ordem afetivo-familiar e social dos alunos passaram a ser conteúdos de sala de aula, sob a responsabilidade dos educadores. O almoço agora é na escola e o intervalo-tempo do meio dia até o início das atividades pedagógicas no turno vespertino deve ser ocupado por atividades formadoras integradoras: atividades culturais, bate papo e rodas de conversa, soneca, jogos, recreação, meditação etc.

Assim, a educação em tempo integral passa a ter princípios e ações próprios a serem realizados no espaço escolar, tais como: a reestruturação da proposta pedagógica, coletivamente construída e não apenas a ampliação do tempo escolar; integração de linguagens e de conhecimento a partir da organização de um currículo amplo, que vise a ações multiculturais e integradoras; construção de projeto de ensino que vise à formação humana. Com este quadro desenhado, a escola passa a assumir tarefas ou responsabilidades dos pais e/ou da família, devendo alterar seu planejamento estratégico ou sua rotina para atender a essas novas demandas, mesmo que não dotada de infraestrutura mínima para acomodação dos educandos ou formação docente para atuar nesses novos contextos educacionais. 
Dessa nova situação, surge uma pergunta: quem deve assumir essas atividades extras na escola? Mais uma vez o professor se sente acuado a ampliar suas funções e seu repertório de conteúdos, buscando até mesmo na sua experiência de pai e mãe de família para dar conta das novas tarefas, pois para ser um bom professor/educador, nesse contexto, é preciso combater a evasão, a repetência, o desinteresse ou dispersão dos alunos em "sete horas de efetivo trabalho pedagógico por dia".

Lidar com pessoas jovens, cheias de vigor e características individuais distintas, oriundas de realidades familiares e sociais em crise ou ausentes em grande medida, enfrentando riscos sociais próprios das comunidades periféricas, convenhamos, dificulta enormemente a tarefa de educar, principalmente quando agrupamos no mesmo espaço de convivência alunos com diversidades intelectual, moral, econômica, social etc. e trazemos as atividades que normalmente eram feitas em família e agora fazem parte, também, do universo escolar.

O ser humano, por ser um conjunto complexo de emoções e de sentimentos que desencadeiam uma série de reações diferentes, com características específicas para cada pessoa, situação e ambiente, apresenta comportamentos diferentes no espaço escolar. Amar, odiar, chorar (de alegria ou tristeza), alegria, tristeza, satisfação, angústia, cada um de nós reage de forma surpreendente aos aspectos que podem promover o mal-estar e, com isso, desestabilizar emocionalmente o sujeito.

Lipp (1991) destaca que emoções e sentimentos são coisas distintas, que geram reações das mais diversas e são desencadeadas por fatores internos e externos. A autora conceitua sentimentos como estados afetivos duradouros e estáveis; constituem estados de emoções de maior duração. Dessa forma, representam modos mais estáveis que servem como pano de fundo para as formas mais agudas e violentas de emoções. A emoção, por outro lado, seria o pico de um sentimento. É uma experiência afetiva, com duração mais breve. Trata-se de um sinal de que alguma coisa no ambiente está diferente do usual.

Embora emoções e sentimentos exerçam papéis importantes em nossa vida, os fatores externos são muito mais fáceis de serem observados do que aqueles que se passam em nosso interior. Então, quando pensamos no estresse emocional, frequentemente, o atribuímos a fatores externos, tais como problemas familiares, no trabalho, no trânsito, das perdas inevitáveis em nossa vida e pensamos que, uma vez terminado o fator desencadeante, o efeito desaparecerá. Entretanto, nem sempre é assim, pois tanto agentes externos quanto internos podem nos provocar situações estressantes. 
Um dos problemas do mal-estar docente é que afeta a identidade do professor já que os diversos fatores externos presentes no cotidiano escolar são de difícil solução e gerados por muitos aspectos, uns de ordem sistêmica, outros sócio-culturais e emocionais e alguns poucos de ordem didática, tais como baixos salários, desvalorização profissional, estrutura física inadequada das escolas, carga horária excessiva, turmas lotadas, ausência da família no apoio e acompanhamento dos educandos e falta de limites dos alunos.

A verdade é que o professor enfrenta situações que desestabilizam suas emoções ou testam sua capacidade de enfrentamento e superação, e todo ambiente escolar afetado por esse mal-estar acaba por colocar em xeque a sua capacidade profissional, levando-o a uma crise de identidade quando diante de situações que fogem ao seu raio de atuação ou vão além da sua competência. Entretanto,o desenvolvimento afetivo de alunos, funcionários, colegas de trabalho, gestão também contribui para o bem-estar do docente que, sem deixar de lado o desenvolvimento cognitivo, dá visibilidade a práticas humanas e emocionais na vivência diária do currículo na educação em tempo integral, tecendo sua identidade e professoralidade na dinâmica da atividade docente.

\section{CONSIDERAÇÕES QUASE FINAIS}

O exercício docente já é por si só desafiante no contexto do século XXI, numa sociedade marcada por valores fugazes e cambiantes e onde a profissionalização docente tem sido atacada de maneira sutil pelo mal-estar que afeta diretamente aos profissionais da educação. As preocupações e angústias recorrentes nos debates sobre a professoralidade e a identidade docente são problematizações necessárias na Educação em Tempo Integral, no sentido de gerar intervenção na realidade, a fim de promover o bem-estar tão necessário ao enfrentamento dos conflitos sistêmico e sociais oriundos da implantação e da continuidade do ProEi.

Dessa forma, este artigo discutiu sobre o mal-estar docente e sua implicação em relação à consolidação da identidade e da professoralidade do professor que atua no Programa. Apresentamos, de forma teórico-conceitual, cenários de um Brasil profundo que, para atender a metas de programas de governo/estado, pouco visualiza e/ou problematiza sentimentos e emoções do professor em seu processo de atuação na escola. Por fim, analisamos como a nova dinâmica escolar, a partir da implantação do ProEi, tem gerado o mal-estar docente, que necessita ser superado a partir da 
valorização e da ampliação da formação do professor.

\section{REFERÊNCIAS}

ANDRÉ, Marli. Etnografia da prática escolar. Campinas: Papirus, 1995

BAHIA. Secretaria de Estado de Educação. Programa de Educação Integral PROEI. Salvador, 2014. Disponível em: http://educacaointegral.org.br/wpcontent/uploads/2016/08/proei-versao-preliminar-1.pdf. Acesso em:15/05/2018.

BATISTA, A. Os professores são não-leitores? In: MARINHO, M.; SILVA, C. S. R. (Orgs.) Leituras do professor. Campinas: ALB/Mercado de Letras, 1998.

BRASIL. Educação integral: texto referência para o debate nacional. Brasília: Mec, Secad, 2009.

BUNZEN, C. Dinâmicas discursivas na aula de português: os usos do livro didático e projeto didáticos autorais. 2009. 227 f. Tese (Doutorado). Departamento de Letras e Linguística. Programa de Pós-Graduação em Linguística Aplicada. Universidade Estadual de Campinas, Campinas, 2009.

CASTRO, A. de; LOPES, R. E.A escola de tempo integral: desafios e possibilidades. Ensaio: aval. pol. públ. Educ., Rio de Janeiro, v. 19, n. 71, p. 259-282, abr.jun. 2011.

CAVALIERE, Ana Maria. Tempo de escola e qualidade na educação pública. Educ. Soc. [online]. 2007, vol.28, n.100, pp.1015-1035. ISSN 0101-7330. http://dx.doi.org/10.1590/S0101-73302007000300018

COELHO, Nelly Novaes. Panorama histórico da literatura infantil/juvenil: das origens indo-europeias ao Brasil contemporâneo. 5. ed. Ver. Atual. São Paulo: Manole, 2010.

CUNHA, Úrsula. Novas tecnologias e ensino: diálogo mais do que possível na escola pública. Anais eletrônicos do $4^{\circ}$ Simpósio Hipertexto e tecnologias na educação. Recife (PE): NEHTE, 2012. Disponível em: http://www.nehte.com.br/simposio/anais/AnaisHipertexto-2012/UrsulaCunha-Novastecnologias.pdf. Acessado em: 15/12/2018.

ELIAS, Nobert. Sobre o Tempo. Rio de Janeiro: Jorge Zahar, 1998.

ESTEVE, José Manuel. O mal-estar docente: a sala de aula e a saúde dos professores. São Paulo: EDUSC, 1999.

FERREIRA, Hugo Monteiro . Elementos constitutivos de uma docência integral. In: Hugo Monteiro Ferreira. (Org.). A educação integral e a transdisciplinaridade. Recife: MXM Gráfica e Editora, 2016, v. 1, p. 37-44.

FREIRE, P. Pedagogia da Esperança: um reencontro com a Pedagogia do Oprimido. Rio de Janeiro: Paz e Terra, 1992

GUIMARÃES, V. S. A formação de professores: saberes, identidade e profissão. Campinas, SP: Papirus, 2004.

ISAIA, S. M. A. BOLZAN, D. P. V. Compreendendo os movimentos construtivos da Docência superior: construções sobre pedagogia universitária. Linhas críticas. Brasília, 8001 Vol.14, N²6, jan-jun, 2008, pp.25-42

JULIÃO, Elionaldo Fernandes. Educação e trabalho como propostas políticade execução penal. revista de Educação de Jovens e Adultos: alfabetização e cidadania, Brasília, n. 19, 2006.

KLEIMAN, A. B. Letramento e formação do professor: quais as práticas e exigências 
no local de trabalho? In KLEIMAN, A. B. A formação do professor: perspectivas da Linguística Aplicada. Campinas: Mercado de Letras, 2001, p. 39-68.

LIPP, Marilda Novaes (Org.). O stress do Professor. Campinas: Papirus, 1991.

MENDES, E. Língua, cultura e formação de professores: por uma abordagem de ensino intercultural. In: MENDES, E.; CASTRO, M. L. S. Saberes em português: ensino e formação docente. Campinas, SP: Pontes, 2008. p. 57-77.

OLIVEIRA, Djalma de Pinho Rebouças de, Planejamento estratégico: conceitos, metodologias e práticas. 19 ed. São Paulo: Atlas, 2003.

PIMENTA, Selma Garrido. Formação de professores: identidade e saberes da docência. In: PIMENTA, Selma Garrido. (Org). Saberes pedagógicos e atividade docente. São Paulo: Cortez Editora, 1997.

PONTE, J. P. da. Investigar a nossa própria prática: Uma estratégia de formação e de construção do conhecimento profissional. In CASTRO, E.; TORRE, E. Investigación en educación matemática. Coruña: Universidad da Coruña. Republicado em 2008, PNA Revista de Investigación en Didáctica de la Matemática, 2(4), p. 153-180.

SACRISTAN, José Gimeno. Consciência e ação sobre a prática como libertação dos professores. In: NÓVOA, Antônio (org.) Profissão Professor. Portugal: Porto Editora, 1995.

TARDIFF, 2003 SACRISTÁN GIMENO, J. Consciência a acção sobre a prática como libertação profissional dos professores. In: NÓVOA, A. (Org.). Profissão professor. Porto: Porto Ed., 1995. p. 63-92

ZABALA, Antonio; ARNAUD, Laia. Como aprender e ensinar competências. Porto Alegre: ArtMed, 2010. 